\title{
Could Wearable and Mobile Technology Improve the Management of Essential Tremor?
}

\author{
Jean-Francois Daneault* \\ Motor Behavior Laboratory, Department of Rehabilitation and Movement Sciences, School of Health Professions, \\ Rutgers, The State University of New Jersey, Newark, NJ, United States
}

Essential tremor (ET) is the most common movement disorder. Individuals exhibit postural and kinetic tremor that worsens over time and patients may also exhibit other motor and non-motor symptoms. While millions of people are affected by this disorder worldwide, several barriers impede an optimal clinical management of symptoms. In this paper, we discuss the impact of ET on patients and review major issues to the optimal management of ET; from the side-effects and limited efficacy of current medical treatments to the limited number of people who seek treatment for their tremor. Then, we propose seven different areas within which mobile and wearable technology may improve the clinical management of ET and review the current state of research in these areas.

Keywords: essential tremor, smartphone, smartwatch, mobile, wearable, technology, movement disorder

\section{OPEN ACCESS INTRODUCTION}

Edited by:

Joaquim Ferreira,

Instituto de Medicina Molecular (IMM), Portugal

Reviewed by: Gertrud Tamas, Semme/weis University, Hungary Antonella Conte, Sapienza Università di Roma, Italy

*Correspondence: Jean-Francois Daneault jf.daneault@rutgers.edu

Specialty section: This article was submitted to Movement Disorders, a section of the journal Frontiers in Neurology

Received: 17 January 2018 Accepted: 03 April 2018 Published: 19 April 2018

Citation: Daneault J-F (2018) Could Wearable and Mobile Technology Improve the Management of Essential Tremor?

Front. Neurol. 9:257. doi: 10.3389/fneur.2018.00257
Essential tremor (ET) is a movement disorder where individuals exhibit bilateral, persistent postural, or kinetic upper-limb tremor (1-4) that can also be observed during rest in some cases (4-9). Tremor amplitude varies greatly between patients and also within one patient from day to day, and within a given day $(10,11)$. Interestingly, tremor amplitude tends to increase with advancing age $(12,13)$. To date, diagnosis of ET is based on clinical examination and neurological history. Very recently, the International Parkinson and Movement Disorders Society Task Force on Tremor has proposed that individuals exhibiting symptoms other than tremor should be labeled as having ET plus syndrome (14). These accompanying neurological signs may include mild to moderate gait ataxia $(3,15-23)$, cognitive impairment $(24,25)$ as well as personality profile $(26-28)$, and mood disturbances (29-31). Thus, ET is no longer considered a benign form of tremor but rather a complex disorder.

ET is the most prevalent movement disorder among adults (32). Its prevalence is markedly higher than that of Parkinson's disease (PD) (33-35) and many "common" neurological diseases such as epilepsy, stroke, and multiple sclerosis (36). The overall prevalence of ET is estimated at $0.9 \%$ (37); suggesting that there are about 70 million individuals with ET worldwide. Prevalence increases markedly with age; such that a rate of $4.6 \%$ in individuals 65 years and older, and a rate of up to $20 \%$ in the oldest old was estimated (37). Therefore, due to the aging population and extended life expectancy, ET is becoming a larger cause of functional disability.

\section{What Is the Impact of ET on Quality of Life?}

Tremor negatively impacts activities of daily living (ADLs) (38); and can lead to embarrassment and stigmatization affecting emotional well-being $(39,40)$. Mild functional impairment due to tremor has been reported in $60-73 \%$ of individuals with ET $(31,41)$ while moderate to severe impairment in everyday life has been reported by $26 \%$ of patients (31). Of note, $5.3 \%$ of individuals with ET reported that they frequently needed help in ADLs because of their tremor. Therefore, millions of individuals experience daily functional impairments due to ET. 
Non-motor symptoms, such as depression and anxiety, are also often observed in individuals with ET; impairing their quality of life (41-43). Higher levels of anxiety are observed among individuals with ET than in healthy individuals (28), and major depressive disorder was diagnosed in $5.4 \%$ of individuals with ET whereas it was only observed in $2.7 \%$ of healthy individuals (41). In patients with ET, depression has been largely attributed to the impact of tremor on ADLs, employment and hobbies as well as the embarrassment caused due to tremor during social interactions. ET can often force individuals to retire or change profession, and become reluctant to leave their homes (31). Taken together, this indicates that tremor severity and non-motor symptoms of ET significantly impair quality of life.

\section{What Are the Current Treatments for ET?}

Medication is the primary intervention utilized to minimize tremor severity in individuals with ET. While several medications can be prescribed (44), propranolol and primidone are the most frequently used (45). However, the effectiveness of medication for management of tremor in ET is quite variable, likely due to several factors including the multiple etiologies of ET (14).

One option for the management of tremor that fails to respond to traditional drug therapy is the injection of botulinum toxin. This approach has been used successfully with the advantage of providing very targeted relief (46-51). Many clinicians will use it as a first line treatment to improve head tremor (51) while others also use botulinum toxin to manage intractable limb tremor. Injections are a relatively safe treatment option and are usually effective in reducing tremor severity.

Aside from drug therapy and toxin injections, surgical options may be considered in individuals suffering from important functional disability. Lesions (52-54) and deep brain stimulation (DBS) (55-61) of the nucleus ventrointermedius (Vim) and neighboring structures are believed to disrupt ET-related pathological oscillations and thereby reduce tremor severity. Generally, Vim DBS leads to reduction of $80 \%$ in tremor severity in about $80 \%$ of cases $(62,63)$.

Another, albeit less conventional, treatment for ET is alcohol. Individuals with ET have a transient diminution of tremor amplitude after drinking alcohol (64-66). Koller and Biary (67) demonstrated that alcohol reduced tremor amplitude by an average of $67 \%$. This response can be observed in a majority of ET patients (68). In addition to reducing tremor amplitude, alcohol was also shown to improve gait ataxia in individuals with ET (69).

Of note, while it is now recognized that patients may not only exhibit tremor but also other motor and non-motor symptoms (ET plus syndrome) (14); and it has been shown that those symptoms negatively impact quality of life, there is no literature examining the specific treatment to address these associated ET symptoms.

\section{What Are the Main Issues with Current Treatments and Other Factors Limiting Optimal Care?}

Only about $50 \%$ of patients have lasting benefit from either propranolol or primidone treatment (70-73). Furthermore, tolerance to those drugs has been reported and their side-effects can be dose-limiting (70-73). A more important issue is that there is no significant difference in quality of life in individuals with ET taking medication from those that do not (42); highlighting the variable efficacy of drug treatments.

In addition to the inherent cost of surgical treatments for ET, there are several issues that also limit their use. For instance, although some studies have demonstrated long-lasting effects of Vim DBS (63), others have observed a gradual loss of tremor control in some patients that probably stems from tolerance to stimulation $(55,61,74-76)$. There are also side-effects to Vim DBS. While they are usually reduced or eliminated by adjusting the stimulation parameters, they occasionally lead to treatment discontinuation (60). Another issue with DBS for ET is that advanced age is a relative exclusion criterion for the surgery (77). However, it is worth noting that new technological developments in stimulation (e.g. directional and adaptive stimulation) and lesion (e.g. focused ultrasound) technology could soon improve clinical outcomes of surgical interventions.

Self-medication with alcohol also poses problems in ET. For instance, to obtain long-lasting benefits, repeated alcohol intake is necessary (66). Thus, some patients with ET eventually develop alcohol use disorder (78). In fact, an incidence of alcohol use disorder of up to $67 \%$ was observed in individuals with ET $(78-80)$. Another issue with alcohol is that it actually minimizes the efficacy of propranolol (81).

The above-mentioned information indicates that the different treatment options for ET come with many potential side-effects. Better understanding the symptoms of ET and the effectiveness of the currently available treatments may improve patients' quality of life as well as help in the development of novel therapeutic strategies.

Another limiting factor to proper management is that although the prevalence of ET is very high (37), individuals with ET rarely seek medical care for the disorder. Community-based epidemiological studies have observed that only between 1 and $27 \%$ of individuals with ET seek medical treatment for tremor $(31,82-84)$. Of those who did seek medical advice, $15 \%$ did so only after significant functional disability had occurred (84). This greatly limits our ability to provide proper care to those individuals.

Finally, the lack of scientific evidence regarding the treatment of symptoms other than tremor in ET plus syndrome is lacking. Therefore, there is a need to further research how to best manage these symptoms to provide optimal outcomes for patients.

\section{IS IT POSSIBLE TO IMPROVE EVIDENCE- BASED APPROACHES TO MANAGE ET USING MOBILE AND WEARABLE TECHNOLOGY?}

Compared to other chronic disorders, there are unfortunately very few studies that have explored the role of mobile and wearable technology in the management of ET. Presented next are seven areas, both within and outside the current treatment algorithm, where mobile and wearable technology may improve patient outcomes (see Figure 1). 


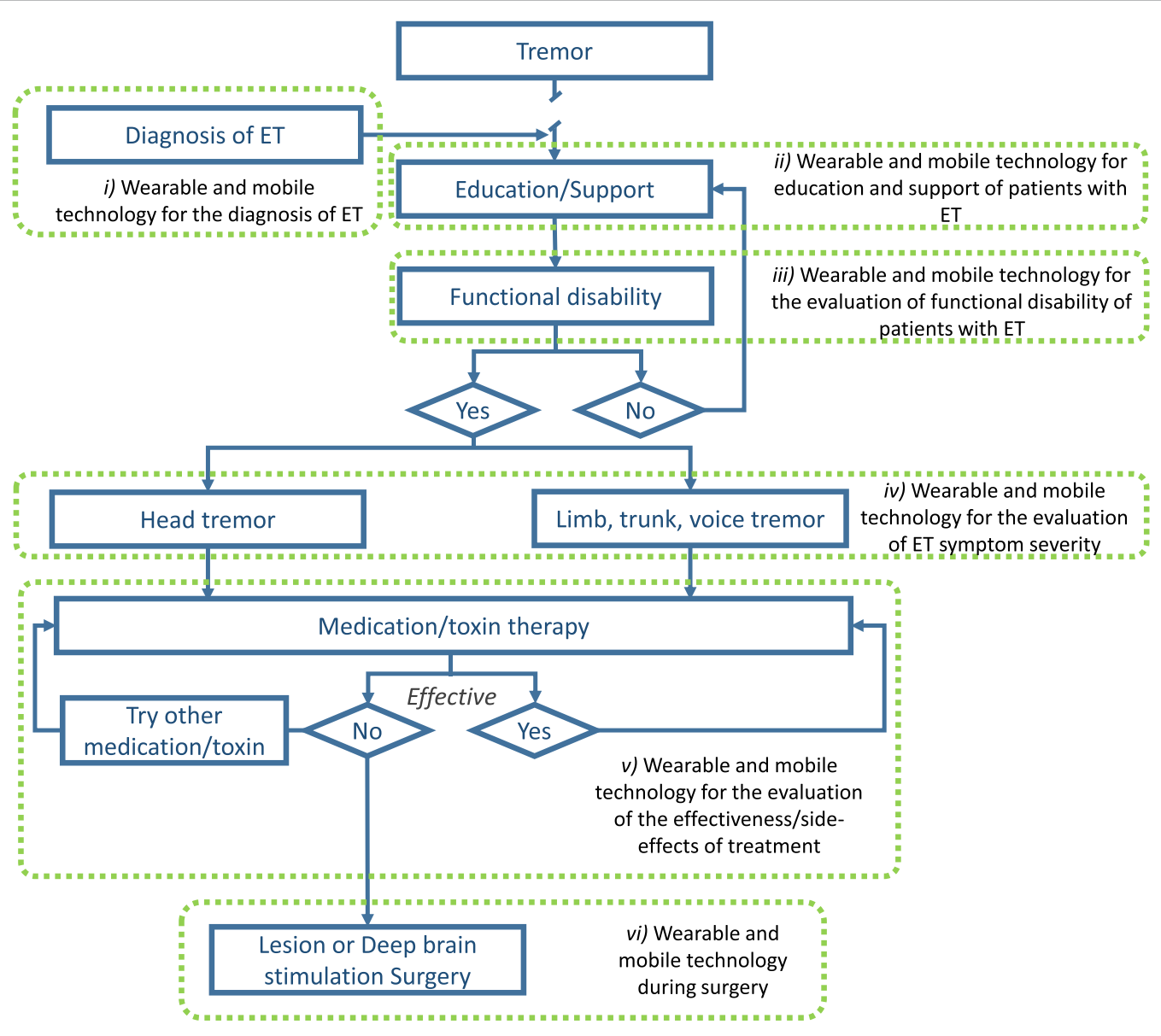

FIGURE 1 | Illustration of areas where wearable and mobile technology could be utilized to improve the management of ET. Adapted from Gironell and Kulisevsky (45) with permission.

\section{Wearable and Mobile Technology for the Diagnosis of ET}

As of today, the most significant barrier to proper management of ET is early and widespread diagnosis. As mentioned above, only a minority of individuals with ET actually seek medical attention and obtain a diagnosis. The ubiquity of technological platforms, such as smartphones and connected devices, may help in the diagnosis of ET. Already, some studies have shown that wearable sensors and smartphones can be utilized to distinguish individuals with ET from healthy individuals and people with PD (85-91). Recent results show an accuracy of $100 \%$ in differentiating both disorders (86). With more data and the development of more sophisticated machine learning algorithms, it may be possible to accurately diagnose ET in the general population using wearable and mobile devices.

\section{Wearable and Mobile Technology for Education and Support of Patients With ET}

Although ET is the most prevalent movement disorder, very few people in the general population are familiar with it. As the disease progresses and symptoms exacerbate, social stigma often leads to negative impacts on quality of life. Educating people about the disease process and preparing them to live with this disorder may help them in the long term. Mobile devices can be used to provide educational and support platforms specifically tailored for patients. While, to our knowledge, the effectiveness of such approaches has yet to be addressed for patient education and support in the movement disorder field, there is an opportunity to improve patient quality of life. For instance, studies have demonstrated the effectiveness of using mobile devices to improve health literacy of individuals with other chronic disorders (92-94) which led, in some cases, to improved clinical outcomes $(93,94)$. Furthermore, recent studies have suggested that peer-to-peer support through social media applications may benefit mental health through interactions with social groups that lead to feelings of belonging and sharing of personal stories/coping strategies (95).

\section{Wearable and Mobile Technology for the Evaluation of Functional Disability of Patients With ET}

The use of wearable technology for the evaluation of functional activities (i.e., ADLs) in patient populations is steadily growing. 
Recently, groups have employed wearable sensors to assess functional activities in stroke survivors (96-98) and individuals with PD $(99,100)$. Much work has been done on using wearable sensor data features to identify daily functional activities in unsupervised conditions using simple wearable technology [e.g., Ref. $(101,102)]$. Being able to identify "what" patients are doing is the first step in recognizing whether they are impaired or not. The next step is to identify "how" patients are doing ADLs. This is a much more complicated task as it is more subjective, and defining task "success" criteria is problematic at best. Nonetheless, some groups have started considering this by identifying wearable sensor features from daily functional tasks that are associated with the overall frailty level of older individuals $(103,104)$. While much work remains to be done, mobile and wearable technology could provide important information regarding when ADLs become impaired.

\section{Wearable and Mobile Technology for the Evaluation of ET Symptom (i.e. Tremor) Severity}

As discussed above, mobile and wearable technology is being used to help in the diagnosis of ET. Studies have focused on identifying several tremor characteristics to help differentiate different tremor disorders because ET clinical diagnosis is based on tremor. Several groups have utilized mobile and wearable technology to assess tremor severity in ET without using it for diagnostic purposes [e.g., Ref. $(105,106)]$ but rather as a tool to monitor the evolution of symptoms over time. This is an area in which technology has an advantage over current clinical approaches because it could provide a better understanding of long-term tremor behavior; over hours, days, weeks, and even months. Clinicians currently use clinical rating scales that can only provide a measure of maximal tremor severity on a very short time window. It is impractical to perform clinical assessments at multiple time points. To get a better understanding of tremor fluctuations over time, clinicians rely heavily on patient recall; which can be misleading $(107,108)$ and suffer from recollection bias. While mobile technology could enable more frequent tremor assessments, wearable technology could provide continuous tremor assessment $(106,109)$. This may inform on the pathophysiological mechanisms underlying ET as well as help clinicians in the titration of medications and prescription of more invasive treatment options.

\section{Wearable and Mobile Technology for the Evaluation of the Effectiveness of Treatment}

As clinicians usually rely on a treatment algorithm (45) to achieve the best possible outcome in tremor reduction in ET, it is pivotal to know how effective a given drug or treatment is in minimizing tremor. As mentioned above, the methods currently in use are clinical rating scales and patient reports which both have limitations. Utilizing mobile and wearable technology prior to treatment initiation or before a treatment modification could provide a solid basis to compare data obtained after the change in patient status and identify whether the treatment was effective in significantly reducing tremor severity. This could inform clinicians as to the effectiveness, if any, of the new intervention. The longitudinal data could help in titrating medication dosage or reduce the time patients must wait prior to moving on to another treatment if the current one is not effective by providing large quantities of objective data. By optimizing the treatment of patients, it could minimize the impact ET has on their ADLs and reduce stigma, thus improving their quality of life.

Wearable and mobile technology may also be useful in the identification of treatment side-effects. Side-effects of ET treatment can sometimes include heart problems and balance disorders; both of which could be identified and monitored using wearable technology $(110,111)$. Recent advances in speech processing (112) also suggest that mobile platforms could be employed to identify and monitor speech characteristics that may be altered by DBS. Wearable and mobile devices therefore have the potential of identifying and monitoring the possible side-effects of ET treatment which could help clinicians optimize treatment outcomes.

\section{Wearable and Mobile Technology During Surgery}

Surgical interventions aimed at alleviating intractable tremor are costly procedures with potentially significant side-effects. It is therefore of the utmost importance to optimize the outcome of such interventions and attempt to minimize their risk. To that end, some groups have started looking into using wearable and mobile technology to support the surgical team in identifying the optimal target location for DBS electrodes (113). While data from wearable devices collected during DBS surgery cannot replace the expertise of an experienced movement disorder specialist, they can provide additional information on objective tremor characteristics to the clinical team about the impact of different stimulation parameters at different locations. This can therefore help surgeons place the lead in a patient-specific optimal location and provide the DBS programming team a good starting point to reduce the time to achieve optimal stimulation parameters. Of note, the same on-line tremor monitoring approach could be utilized for lesion approaches.

\section{Wearable and Mobile Technology for the Evaluation of ET Symptom Severity Other Than Tremor}

As discussed above, patients with ET plus syndrome may exhibit gait ataxia $(3,15-23)$ as well as cognitive impairment $(24,25)$, personality profile (26-28), and mood disturbances (29-31). Gait ataxia can be reliably assessed using wearable sensors in individuals with spinocerebellar degeneration (111) and thus, with some work could reasonably also be utilized to assess this issue in patients with ET. On the other hand, much less work has been done to use wearable and mobile technology to assess the severity of non-motor symptoms. Some groups have developed mobile applications to assess cognitive function in different populations $(114,115)$. While this shows promise, these studies were in the proof-of-principle phase therefore, more work is required to 
assess whether mobile technology can be used to provide reliable assessments of cognitive function. As for the assessment of personality profile and mood disturbances, there are groups that have monitored physiological signals such as heart rate variability and skin conductance to assess psychological function in different populations (116-118). The very limited evidence concerning the use of mobile and wearable technology for the assessment and management of non-motor symptoms highlights the opportunities in this field. The development of such tools would benefit not only individuals with ET but also several other patient populations.

\section{Challenges to the Use of Wearable and Mobile Technology for the Management of ET}

While the opportunities for the use of wearable and mobile technology in the management of ET are very promising, there are also challenges that need to be addressed before widespread adoption of this technology can be envisioned.

While the storage capacity of commercially available systems is continually expanding and opportunities to store large quantities of data in the cloud become more readily available, our ability to analyze these datasets to provide clinically relevant information to clinicians and patients remains limited at this time (119). Collaborative efforts between engineers, computer scientists, and clinicians are required to identify the relevant information that can be extracted from the data using novel signal processing and machine learning algorithms.

Another important barrier to wider implementation of mobile and wearable technology for home or long-term monitoring is

\section{REFERENCES}

1. Bhidayasiri R. Differential diagnosis of common tremor syndromes. Postgrad Med J (2005) 81:756-62. doi:10.1136/pgmj.2005.032979

2. Louis ED, Ford B, Wendt KJ, Cameron G. Clinical characteristics of essential tremor: data from a community-based study. Mov Disord (1998) 13:803-8. doi:10.1002/mds.870130508

3. Hubble JP, Busenbark KL, Pahwa R, Lyons K, Koller WC. Clinical expression of essential tremor: effects of gender and age. Mov Disord (1997) 12:969-72. doi:10.1002/mds.870120620

4. Daneault JF, Carignan B, Rahimi F, Sadikot AF, Duval C. Postural tremors. In: Grimaldi G, Manto M, editors. Mechanisms and Emerging Therapies in Tremor Disorders. New York: Springer Science+Business Media (2013). p. 133-50.

5. Louis ED, Applegate LK, Factor-Litvak P, Parides MK. Factor structure of motor signs in essential tremor. Neuroepidemiology (2005) 25:42-7. doi: $10.1159 / 000085312$

6. Gironell A, Kulisevsky J, Pascual-Sedano B, Barbanoj M. Routine neurophysiologic tremor analysis as a diagnostic tool for essential tremor: a prospective study. J Clin Neurophysiol (2004) 21:446-50. doi:10.1097/ 00004691-200411000-00009

7. Burne JA, Blanche T, Morris JJ. Muscle loading as a method to isolate the underlying tremor components in essential tremor and Parkinson's disease. Muscle Nerve (2004) 30:347-55. doi:10.1002/mus.20109

8. Cohen O, Pullman S, Jurewicz E, Watner D, Louis ED. Rest tremor in patients with essential tremor: prevalence, clinical correlates, and electrophysiologic characteristics. Arch Neurol (2003) 60:405-10. doi:10.1001/archneur. 60.3.405 patient compliance. Studies have shown that while patients can utilize wearable sensors for long-term monitoring (120, 121), some patients eventually find those devices uncomfortable and/ or burdensome (120). This highlights the fact that, in designing wearable sensors and mobile applications, it may be beneficial to involve the target patient population to optimize those technologies to their needs and expectations.

\section{CONCLUSION}

ET is already the most common movement disorder and its prevalence will undoubtedly increase over the next years due to the aging population. Because ET is no longer considered a benign disorder and its negative impact on patients' quality of life has been thoroughly examined, there is now a need to identify new and innovative ways to manage the disease to minimize its burden. Based on the current state of mobile and wearable technology, their ubiquity could be leveraged to improve quality of life of patients if clinicians, engineers, and computer scientists work collaboratively on addressing the current gaps in knowledge and performing larger studies to validate outcome measures.

\section{AUTHOR CONTRIBUTIONS}

JF-D conceived, designed, and wrote the manuscript.

\section{ACKNOWLEDGMENTS}

The author would like to thank Gloria Vergara-Diaz for her feedback that helped improve the current manuscript.

9. Dotchin CL, Walker RW. The prevalence of essential tremor in rural northern Tanzania. J Neurol Neurosurg Psychiatry (2008) 79:1107-9. doi:10.1136/ jnnp.2007.134304

10. Tamás G, Pálvölgyi L, Takáts A, Szirmai I, Kamondi A. Contralateral voluntary hand movement inhibits human parkinsonian tremor and variably influences essential tremor. Neurosci Lett (2004) 357:187-90. doi:10.1016/j. neulet.2003.12.092

11. Cleeves L, Findley LJ. Variability in amplitude of untreated essential tremor. J Neurol Neurosurg Psychiatry (1987) 50:704-8. doi:10.1136/jnnp.50.6.704

12. Zesiewicz TA, Hauser RA. Phenomenology and treatment of tremor disorders. Neurol Clin (2001) 19:651-80. doi:10.1016/S0733-8619(05)70039-6

13. Hellwig B, Mund P, Schelter B, Guschlbauer B, Timmer J, Lücking CH. A longitudinal study of tremor frequencies in Parkinson's disease and essential tremor. Clin Neurophysiol (2009) 120:431-5. doi:10.1016/j.clinph. 2008.11.002

14. Bhatia KP, Bain P, Bajaj N, Elble RJ, Hallett M, Louis ED, et al. Consensus statement on the classification of tremors, from the task force on tremor of the International Parkinson and Movement Disorder Society. Mov Disord (2017) 33(1):75-87. doi:10.1002/mds.27121

15. Kronenbuerger M, Konczak J, Ziegler W, Buderath P, Frank B, Coenen VA, et al. Balance and motor speech impairment in essential tremor. Cerebellum (2009) 8:389-98. doi:10.1007/s12311-009-0111-y

16. Earhart GM, Clark BR, Tabbal SD, Perlmutter JS. Gait and balance in essential tremor: variable effects of bilateral thalamic stimulation. Mov Disord (2009) 24:386-91. doi:10.1002/mds.22356

17. Parisi SL, Héroux ME, Culham EG, Norman KE. Functional mobility and postural control in essential tremor. Arch Phys Med Rehabil (2006) 87:1357-64. doi:10.1016/j.apmr.2006.07.255 
18. Stolze H, Petersen G, Raethjen J, Wenzelburger R, Deuschl G. The gait disorder of advanced essential tremor. Brain (2001) 124:2278-86. doi:10.1093/ brain/124.11.2278

19. Hoskovcová M, Ulmanová O, Šprdlík O, Sieger T, Nováková J, Jech R, et al. Disorders of balance and gait in essential tremor are associated with midline tremor and age. Cerebellum (2013) 12:27-34. doi:10.1007/s12311-012-0384-4

20. Louis ED, Rios E, Rao AK. Tandem gait performance in essential tremor: clinical correlates and association with midline tremors. Mov Disord (2010) 25:1633-8. doi:10.1002/mds. 23144

21. Rao AK, Uddin J, Gillman A, Louis ED. Cognitive motor interference during dual-task gait in essential tremor. Gait Posture (2013) 38:403-9. doi:10.1016/j. gaitpost.2013.01.006

22. Singer C, Sanchez-Ramos J, Weiner WJ. Gait abnormality in essential tremor. Mov Disord (1994) 9:193-6. doi:10.1002/mds.870090212

23. Louis ED, Galecki M, Rao AK. Brief reports four essential tremor cases with moderately impaired gait: how impaired can gait be in this disease? Tremor Other Hyperkinet Mov (N Y) (2013) 3:1-4. doi:10.7916/d8qv3k7g

24. Tröster AI, Woods SP, Fields JA, Lyons KE, Pahwa R, Higginson CI, et al. Neuropsychological deficits in essential tremor: an expression of cerebellothalamo-cortical pathophysiology? Eur J Neurol (2002) 9:143-51. doi:10.1046/j. 1468-1331.2002.00341.x

25. Benito-León J, Louis ED, Bermejo-Pareja F; Neurological Disorders in Central Spain (NEDICES) Study Group. Population-based case-control study of cognitive function in essential tremor. Neurology (2006) 66:69-74. doi:10.1212/01.wnl.0000192393.05850.ec

26. Thenganatt MA, Louis ED. Personality profile in essential tremor: a casecontrol study. Parkinsonism Relat Disord (2012) 18:1042-4. doi:10.1016/j. parkreldis.2012.05.015

27. Chatterjee A, Jurewicz EC, Applegate LM, Louis ED. Personality in essential tremor: further evidence of non-motor manifestations of the disease. J Neurol Neurosurg Psychiatry (2004) 75:958-61. doi:10.1136/jnnp.2004.037176

28. Tan EK, Fook-Chong S, Lum SY, Gabriel C, Koh KK, Prakash KM, et al. Non-motor manifestations in essential tremor: use of a validated instrument to evaluate a wide spectrum of symptoms. Parkinsonism Relat Disord (2005) 11:375-80. doi:10.1016/j.parkreldis.2005.04.007

29. Louis ED, Benito-León J, Bermejo-Pareja F; Neurological Disorders in Central Spain (NEDICES) Study Group. Self-reported depression and anti-depressant medication use in essential tremor: cross-sectional and prospective analyses in a population-based study. Eur J Neurol (2007) 14:1138-46. doi:10.1111/j.1468-1331.2007.01923.x

30. Miller KM, Okun MS, Fernandez HF, Jacobson CE IV, Rodriguez RL, Bowers D. Depression symptoms in movement disorders: comparing Parkinson's disease, dystonia, and essential tremor. Mov Disord (2007) 22:666-72. doi:10.1002/ mds. 21376

31. Lorenz D, Poremba C, Papengut F, Schreiber S, Deuschl G. The psychosocial burden of essential tremor in an outpatient- and a community-based cohort. Eur J Neurol (2011) 18:972-9. doi:10.1111/j.1468-1331.2010.03295.x

32. Louis ED, Ottman R, Allen Hauser W. How common is the most common adult movement disorder? Estimates of the prevalence of essential tremor throughout the world. Mov Disord (1998) 13:5-10. doi:10.1002/ mds.870130105

33. Chih Liu H, Jiun Wang S, Ling Fuh J, Yia Liu C, Ping Lin K, Huai Lin C, et al. The kinmen neurological disorders survey (KINDS): a study of a Chinese population. Neuroepidemiology (1997) 16:60-8. doi:10.1159/000109672

34. Al Rajeh S, Bademosi O, Ismail H, Awada A, Dawodu A, Al-Freihi H, et al. A community survey of neurological disorders in Saudi Arabia: the Thugbah Study. Neuroepidemiology (1993) 12:164-78. doi:10.1159/000110316

35. Louis ED, Thawani SP, Andrews HF. Prevalence of essential tremor in a multiethnic, community-based study in northern Manhattan, New York, N.Y. Neuroepidemiology (2009) 32:208-14. doi:10.1159/000195691

36. MacDonald BK, Cockerell OC, Sander JW, Shorvon SD. The incidence and lifetime prevalence of neurological disorders in a prospective community-based study in the UK. Brain (2000) 123(Pt 4):665-76. doi:10.1093/ brain/123.4.665

37. Louis ED, Ferreira JJ. How common is the most common adult movement disorder? Update on the worldwide prevalence of essential tremor. Mov Disord (2010) 25:534-41. doi:10.1002/mds.22838

38. Tröster AI, Pahwa R, Fields JA, Tanner CM, Lyons KE. Quality of life in essential tremor questionnaire (QUEST): development and initial validation.
Parkinsonism Relat Disord (2005) 11:367-73. doi:10.1016/j.parkreldis. 2005.05.009

39. George MS, Bruce Lydiard R. Social phobia secondary to physical disability: a review of benign essential tremor (BET) and stuttering. Psychosomatics (1994) 35:520-3. doi:10.1016/S0033-3182(94)71720-5

40. Schneier FR, Barnes LF, Albert SM, Louis ED. Characteristics of social phobia among persons with essential tremor. J Clin Psychiatry (2001) 62:367-72. doi:10.4088/JCP.v62n0511

41. Louis ED, Barnes L, Albert SM, Cote L, Schneier FR, Pullman SL, et al. Correlates of functional disability in essential tremor. Mov Disord (2001) 16:914-20. doi:10.1002/mds.1184

42. Chandran V, Pal PK. Quality of life and its determinants in essential tremor. Parkinsonism Relat Disord (2013) 19:62-5. doi:10.1016/j.parkreldis. 2012.06.011

43. Chandran V, Pal PK, Reddy JYC, Thennarasu K, Yadav R, Shivashankar N. Non-motor features in essential tremor. Acta Neurol Scand (2012) 125:332-7. doi:10.1111/j.1600-0404.2011.01573.x

44. Sadeghi R, Ondo WG. Pharmacological management of essential tremor. Drugs (2010) 70:2215-28. doi:10.2165/11538180-000000000-00000

45. Gironell A, Kulisevsky J. Diagnosis and management of essential tremor and dystonic tremor. Ther Adv Neurol Disord (2009) 2:215-22. doi:10.1177/ 1756285609104791

46. Jankovic J, Schwartz K. Botulinum toxin treatment of tremors. Neurology (1991) 41:1185-8. doi:10.1212/WNL.41.8.1185

47. Jankovic J, Schwartz K, Clemence W, Aswad A, Mordaunt J. A randomized, double-blind, placebo-controlled study to evaluate botulinum toxin type A in essential hand tremor. Mov Disord (1996) 11:250-6. doi:10.1002/ mds. 870110306

48. Brin MF, Lyons KE, Doucette J, Adler CH, Caviness JN, Comella CL, et al. A randomized, double masked, controlled trial of botulinum toxin type A in essential hand tremor. Neurology (2001) 56:1523-8. doi:10.1212/WNL. 56.11 .1523

49. Zakin E, Simpson D. Botulinum toxin in management of limb tremor. Toxins (Basel) (2017) 9(11):365. doi:10.3390/toxins9110365

50. Pacchetti C, Mancini F, Bulgheroni M, Zangaglia R, Cristina S, Sandrini G, et al. Botulinum toxin treatment for functional disability induced by essential tremor. Neurol Sci (2000) 21:349-53. doi:10.1007/s100720070049

51. Pahwa R, Busenbark K, Swanson-Hyland EF, Dubinsky RM, Hubble JP, Gray C, et al. Botulinum toxin treatment of essential head tremor. Neurology (1995) 45:822-4. doi:10.1212/WNL.45.4.822

52. Goldman MS, Kelly PJ. Symptomatic and functional outcome of stereotactic ventralis lateralis thalamotomy for intention tremor. J Neurosurg (1992) 77:223-9. doi:10.3171/jns.1992.77.2.0223

53. Kondziolka D, Ong JG, Lee JYK, Moore RY, Flickinger JC, Lunsford LD. Gamma knife thalamotomy for essential tremor. JNeurosurg (2008) 108: 111-7. doi:10.3171/JNS/2008/108/01/0111

54. Shahzadi S, Tasker RR, Lozano A. Thalamotomy for essential and cerebellar tremor. Stereotactic Funct Neurosurg (1995) 65(1-4):11-7. doi:10.1159/000098890

55. Blomstedt P, Hariz G-M, Hariz MI, Koskinen L-OD. Thalamic deep brain stimulation in the treatment of essential tremor: a long-term follow-up. Br J Neurosurg (2007) 21:504-9. doi:10.1080/02688690701552278

56. Della Flora E, Perera C, Cameron A, Maddern G. Deep brain stimulation for essential tremor: a systematic review. Mov Disord (2010) 25:1550-9. doi: $10.1002 / \mathrm{mds} .23195$

57. Lee JYK, Kondziolka D. Thalamic deep brain stimulation for management of essential tremor. J Neurosurg (2005) 103:400-3. doi:10.3171/jns.2005. 103.3.0400

58. Lyons KE, Pahwa R. Deep brain stimulation and essential tremor. J Clin Neurophysiol (2004) 21:2-5.

59. Nazzaro JM, Lyons KE, Pahwa R. Deep brain stimulation for essential tremor. Handb Clin Neurol (2013) 116:156-66. doi:10.1016/B978-0-444-53497-2.00013-9

60. Putzke JD, Wharen RE, Obwegeser AA, Wszolek ZK, Lucas JA, Turk MF, et al. Thalamic deep brain stimulation for essential tremor: recommendations for long-term outcome analysis. Can J Neurol Sci (2004) 31:333-42. doi:10.1017/S0317167100003413

61. Zhang K, Bhatia S, Oh MY, Cohen D, Angle C, Whiting D. Long-term results of thalamic deep brain stimulation for essential tremor. J Neurosurg (2010) 112:1271-6. doi:10.3171/2009.10.jns09371 
62. Munhoz RP, Picillo M, Fox SH, Bruno V, Panisset M, Honey CR, et al. Eligibility criteria for deep brain stimulation in Parkinson's disease, tremor, and dystonia. Can J Neurol Sci (2016) 43:462-71. doi:10.1017/cjn.2016.35

63. Deuschl G, Raethjen J, Hellriegel H, Elble R. Treatment of patients with essential tremor. Lancet Neurol (2011) 10:148-61. doi:10.1016/S1474-4422 (10)70322-7

64. Critchley M. Observations on essential (heredofamilial) tremor. Brain (1949) 72:113-39. doi:10.1093/brain/72.2.113

65. Koller WC, Hristova A, Brin M. Pharmacologic treatment of essential tremor. Neurology (2000) 54:S30-8. doi:10.1212/WNL.54.9.30A

66. Growdon JH, Shahani BT, Young RR. The effect of alcohol on essential tremor. Neurology (1975) 25:259-62. doi:10.1212/WNL.25.3.259

67. Koller WC, Biary N. Effect of alcohol on tremors: comparison with propranolol. Neurology (1984) 34:221-2. doi:10.1212/WNL.34.2.221

68. Lou JS, Jankovic J. Essential tremor: clinical correlates in 350 patients. Neurology (1991) 41:234-8. doi:10.1212/WNL.41.2_Part_1.234

69. Klebe S, Stolze H, Grensing K, Volkmann J, Wenzelburger R, Deuschl G. Influence of alcohol on gait in patients with essential tremor. Neurology (2005) 65:96-101. doi:10.1212/01.wnl.0000167550.97413.1f

70. Sasso E, Perucca E, Fava R, Calzetti S. Quantitative comparison of barbiturates in essential hand and head tremor. Mov Disord (1991) 6:65-8. doi:10.1002/ mds. 870060112

71. O'Suilleabhain P, Dewey RB. Randomized trial comparing primidone initiation schedules for treating essential tremor. Mov Disord (2002) 17:382-6. doi: $10.1002 / \mathrm{mds} .10083$

72. Koller WC, Royse VL. Efficacy of primidone in essential tremor. Neurology (1986) 36:121-4. doi:10.1212/WNL.36.1.121

73. Koller WC, Vetere-overfield B. Acute and chronic effects of propranolol and primidone in essential tremor. Neurology (1989) 39:1587-1587. doi:10.1212/ WNL.39.12.1587

74. Pilitsis JG, Metman LV, Toleikis JR, Hughes LE, Sani SB, Bakay RAE. Factors involved in long-term efficacy of deep brain stimulation of the thalamus for essential tremor. J Neurosurg (2008) 109:640-6. doi:10.3171/ JNS/2008/109/10/0640

75. Pahwa R, Lyons KE, Wilkinson SB, Simpson RK, Ondo WG, Tarsy D, et al. Long-term evaluation of deep brain stimulation of the thalamus. J Neurosurg (2006) 104:506-12. doi:10.3171/jns.2006.104.4.506

76. Kumar R, Lozano AM, Sime E, Lang AE. Long-term follow-up of thalamic deep brain stimulation for essential and parkinsonian tremor. Neurology (2003) 61:1601-4. doi:10.1212/01.WNL.0000096012.07360.1C

77. Fasano A, Herzog J, Deuschl G. Selecting appropriate tremor patients for DBS. In: Bain P, Aziz T, Liu X, Nandi D, editors. Deep Brain Stimulation. Oxford, UK: Oxford University Press (2009). doi:10.1093/ med/9780199543717.003.0016

78. Nasrallah HA, Schroeder D, Petty F. Alcoholism secondary to essential tremor. J Clin Psychiatry (1982) 43:163-4.

79. Bain PG, Findley LJ, Thompson PD, Gresty MA, Rothwell JC, Harding AE, et al. A study of hereditary essential tremor. Brain (1994) 117:805-24. doi:10.1093/brain/117.4.805

80. Rajput AH, Offord KP, Beard CM, Kurland LT. Essential tremor in Rochester, Minnesota: a 45-year study. J Neurol Neurosurg Psychiatry (1984) 47:466-70. doi:10.1136/jnnp.47.5.466

81. Goldman V, Comerford B, Hughes D, Nyberg G. Effect of $\beta$-adrenergic blockade and alcohol on simulated car driving. Nature (1969) 224:1175-8. doi:10.1038/2241175a0

82. Larsson T, Sjogren T. Essential tremor: a clinical and genetic population study. Acta Psychiatr Scand Suppl (1960) 36:1-176.

83. Dogu O, Louis ED, Sevim S, Kaleagasi H, Aral M. Clinical characteristics of essential tremor in Mersin, Turkey: a population-based door-to-door study. J Neurol (2005) 252:570-4. doi:10.1007/s00415-005-0700-8

84. Rautakorpi I, Takala J, Marttila RJ, Sievers K, Rinne UK. Essential tremor in a Finnish population. Acta Neurol Scand (1982) 66:58-67. doi:10.1111/j.1600-0404. 1982.tb03129.x

85. Woods AM, Nowostawski M, Franz EA, Purvis M. Parkinson's disease and essential tremor classification on mobile device. Pervasive Mob Comput (2014) 13:1-12. doi:10.1016/j.pmcj.2013.10.002

86. Surangsrirat D, Thanawattano C, Pongthornseri R, Dumnin S, Anan C, Bhidayasiri R. Support vector machine classification of Parkinson's disease and essential tremor subjects based on temporal fluctuation. 2016 IEEE 38th
Annual International Conference of the Engineering in Medicine and Biology Society (EMBC). Orlando, FL, USA: IEEE (2016).

87. Locatelli P, Alimonti D. Differentiating essential tremor and Parkinson's disease using a wearable sensor-a pilot study. 2017 7th IEEE International Workshop on Advances in Sensors and Interfaces (IWASI). Vieste, Italy: IEEE (2017).

88. Thanawattano C, Anan C, Pongthornseri R, Dumnin S, Bhidayasiri R. Temporal fluctuation analysis of tremor signal in Parkinson's disease and essential tremor subjects. Proceedings of the Annual International Conference of the IEEE Engineering in Medicine and Biology Society, EMBS (2015). p. 6054-7.

89. Thanawattano C, Pongthornseri R, Anan C, Dumnin S, Bhidayasiri R. Temporal fluctuations of tremor signals from inertial sensor: a preliminary study in differentiating Parkinson's disease from essential tremor. Biomed Eng Online (2015) 14:101. doi:10.1186/s12938-015-0098-1

90. Barrantes S, Sánchez Egea AJ, González Rojas HA, Martí MJ, Compta Y, Valldeoriola F, et al. Differential diagnosis between Parkinson's disease and essential tremor using the smartphone's accelerometer. PLoS One (2017) 12(8):e0183843. doi:10.1371/journal.pone.0183843

91. Wile DJ, Ranawaya R, Kiss ZHT. Smart watch accelerometry for analysis and diagnosis of tremor. J Neurosci Methods (2014) 230:1-4. doi:10.1016/j. jneumeth.2014.04.021

92. MacKert M, Love B, Whitten P. Patient education on mobile devices: an e-health intervention for low health literate audiences. J Inf Sci (2009) 35:82-93. doi:10.1177/0165551508092258

93. Hamine S, Gerth-Guyette E, Faulx D, Green BB, Ginsburg AS. Impact of mHealth chronic disease management on treatment adherence and patient outcomes: a systematic review. J Med Internet Res (2015) 17(2):e52. doi:10.2196/jmir.3951

94. Whitehead L, Seaton P. The effectiveness of self-management mobile phone and tablet apps in long-term condition management: a systematic review. J Med Internet Res (2016) 18(5):e97. doi:10.2196/jmir.4883

95. Naslund JA, Aschbrenner KA, Marsch LA, Bartels SJ. The future of mental health care: peer-to-peer support and social media. Epidemiol Psychiatr Sci (2016) 25:113-22. doi:10.1017/S2045796015001067

96. Lau HY, Tong KY, Zhu H. Support vector machine for classification of walking conditions of persons after stroke with dropped foot. Hum Mov Sci (2009) 28:504-14. doi:10.1016/j.humov.2008.12.003

97. Laudanski A, Brouwer B, Li Q. Activity classification in persons with stroke based on frequency features. Med Eng Phys (2015) 37:180-6. doi:10.1016/j. medengphy.2014.11.008

98. Bochniewicz EM, Emmer G, McLeod A, Barth J, Dromerick AW, Lum P. Measuring functional arm movement after stroke using a single wrist-worn sensor and machine learning. J Stroke Cerebrovasc Dis (2017) 26:2880-7. doi:10.1016/j.jstrokecerebrovasdis.2017.07.004

99. Salarian A, Russmann H, Vingerhoets FJG, Burkhard PR, Aminian K. Ambulatory monitoring of physical activities in patients with Parkinson's disease. IEEE Trans Biomed Eng (2007) 54:2296-9. doi:10.1109/TBME.2007. 896591

100. Toosizadeh N, Mohler J, Lei H, Parvaneh S, Sherman S, Najafi B. Motor performance assessment in Parkinson's disease: association between objective in-clinic, objective in-home, and subjective/semi-objective measures. PLoS One (2015) 10(4):e0124763. doi:10.1371/journal.pone.0124763

101. Lee SI, Ozsecen MY, Della Toffola L, Daneault JF, Puiatti A, Patel S, et al. Activity detection in uncontrolled free-living conditions using a single accelerometer. 2015 IEEE 12th International Conference on Wearable and Implantable Body Sensor Networks, BSN 2015 (2015).

102. Sasaki JE, Hickey AM, Staudenmayer JW, John D, Kent JA, Freedson PS. Performance of activity classification algorithms in free-living older adults. Med Sci Sports Exerc (2016) 48:941-9. doi:10.1249/MSS.0000000000000844

103. Schwenk M, Mohler J, Wendel C, D’Huyvetter K, Fain M, Taylor-Piliae R, et al. Wearable sensor-based in-home assessment of gait, balance, and physical activity for discrimination of frailty status: baseline results of the Arizona frailty cohort study. Gerontology (2015) 61:258-67. doi:10.1159/0003 69095

104. Parvaneh S, Mohler J, Toosizadeh N, Grewal GS, Najafi B. Postural transitions during activities of daily living could identify frailty status: application of wearable technology to identify frailty during unsupervised condition. Gerontology (2017) 63:479-87. doi:10.1159/000460292 
105. Daneault JF, Carignan B, Codère CE, Sadikot AF, Duval C. Using a smart phone as a standalone platform for detection and monitoring of pathological tremors. Front Hum Neurosci (2013) 6:357. doi:10.3389/fnhum.2012.00357

106. Pulliam CL, Eichenseer SR, Goetz CG, Waln O, Hunter CB, Jankovic J, et al. Continuous in-home monitoring of essential tremor. Parkinsonism Relat Disord (2014) 20:37-40. doi:10.1016/j.parkreldis.2013.09.009

107. Louis ED, Ford B, Wendt KJ, Ottman R. Validity of family history data on essential tremor. Mov Disord (1999) 14:456-61. doi:10.1002/1531-8257 (199905)14:3<456::AID-MDS1011>3.0.CO;2-X

108. PrakashKM,TanEK.Validityoffamilyhistoryinessentialtremor.Parkinsonism Relat Disord (2008) 14:151-3. doi:10.1016/j.parkreldis.2007.05.007

109. Zheng X, Campos AV, Ordieres-Meré J, Balseiro J, Marcos SL, Aladro Y. Continuous monitoring of essential tremor using a portable system based on smartwatch. Front Neurol (2017) 8:96. doi:10.3389/fneur.2017.00096

110. Kakria P, Tripathi NK, Kitipawang P. A real-time health monitoring system for remote cardiac patients using smartphone and wearable sensors. Int J Telemed Appl (2015) 2015:373474. doi:10.1155/2015/373474

111. Terayama K, Sakakibara R, Ogawa A. Wearable gait sensors to measure ataxia due to spinocerebellar degeneration. Neurol Clin Neurosci (2017) 6:9-12. doi:10.1111/ncn3.12174

112. Guidi A, Salvi S, Ottaviano M, Gentili C, Bertschy G, de Rossi D, et al. Smartphone application for the analysis of prosodic features in running speech with a focus on bipolar disorders: system performance evaluation and case study. Sensors (Basel) (2015) 15:28070-87. doi:10.3390/s151128070

113. Dai H, D'Angelo LT. Quantitative assessment of tremor during deep brain stimulation using a wearable glove system. 2013 IEEE International Conference on Sensing, Communications and Networking (SECON) (2013). p. $81-5$.

114. Brouillette RM, Foil H, Fontenot S, Correro A, Allen R, Martin CK, et al. Feasibility, reliability, and validity of a smartphone based application for the assessment of cognitive function in the elderly. PLoS One (2013) 8:e65925. doi:10.1371/journal.pone.0065925

115. Jongstra S, Wijsman LW, Cachucho R, Hoevenaar-Blom MP, Mooijaart SP, Richard E. Cognitive testing in people at increased risk of dementia using a smartphone app: the iVitality proof-of-principle study. JMIR Mhealth Uhealth (2017) 5:e68. doi:10.2196/mhealth.6939

116. van Lier HG, Oberhagemann M, Stroes JD, Enewoldsen NM, Pieterse ME, Schraagen JMC, et al. Design decisions for a real time, alcohol craving study using physio- and psychological measures. Lecture Notes in Computer Science (Including Subseries Lecture Notes in Artificial Intelligence and Lecture Notes in Bioinformatics) (2017). p. 3-15.

117. Alam MAU, Roy N, Holmes S, Gangopadhyay A, Galik E. Automated functional and behavioral health assessment of older adults with dementia. 2016 IEEE First International Conference on Connected Health: Applications, Systems and Engineering Technologies (CHASE) (2016). p. 140-9.

118. Kikhia B, Stavropoulos TG, Andreadis S, Karvonen N, Kompatsiaris I, Sävenstedt S, et al. Utilizing a wristband sensor to measure the stress level for people with dementia. Sensors (Basel) (2016) 16:1989. doi:10.3390/s16121989

119. Espay AJ, Bonato P, Nahab FB, Maetzler W, Dean JM, Klucken J, et al. Technology in Parkinson's disease: challenges and opportunities. Mov Disord (2016) 31:1272-82. doi:10.1002/mds.26642

120. Fisher JM, Hammerla NY, Rochester L, Andras P, Walker RW. Body-worn sensors in Parkinson's disease: evaluating their acceptability to patients. Telemed J E Health (2016) 22:63-9. doi:10.1089/tmj.2015.0026

121. Ferreira JJ, Godinho C, Santos AT, Domingos J, Abreu D, Lobo R, et al. Quantitative home-based assessment of Parkinson's symptoms: the SENSEPARK feasibility and usability study. BMC Neurol (2015) 15:89. doi:10.1186/ s12883-015-0343-z

Conflict of Interest Statement: The author declares that he owns shares and is a co-founder of Medapplets.

Copyright (c) 2018 Daneault. This is an open-access article distributed under the terms of the Creative Commons Attribution License (CC BY). The use, distribution or reproduction in other forums is permitted, provided the original author(s) and the copyright owner are credited and that the original publication in this journal is cited, in accordance with accepted academic practice. No use, distribution or reproduction is permitted which does not comply with these terms. 